\title{
Effect of Magnetic Field on Flow and Heat Transfer over a Stretching Hori- zontal Cylinder in the Presence of a Heat Source/Sink with Suction/Injection
}

Elsayed MA Elbashbeshy ${ }^{1 *}$, TG Emam² ${ }^{2}$ MS EI-Azab ${ }^{3}$ and KM Abdelgaber ${ }^{4}$

${ }^{1}$ Mathematics Department, Faculty of Science, Ain Shams University, Abbassia, Cairo, Egypt

${ }^{2}$ Mathematics Department, The German University in Cairo - GUC, New Cairo City, Cairo, Egypt

${ }^{3}$ Department of Physics \& Engineering Mathematics, Faculty of Engineering, Mansoura University, Mansoura, Egypt

${ }^{4}$ Department of Physics \& Engineering Mathematics, Faculty of Engineering - Mataria, Helwan University, Cairo, Egypt

\begin{abstract}
Effect of magnetic field on flow and heat transfer of an incompressible viscous fluid over a stretching horizontal cylinder in the presence of heat source or sink with suction/injection is discussed numerically. The governing boundary layer equations are reduced to a system of ordinary differential equations. Mathematica has been used to solve such system after obtaining the missed initial conditions. Comparison of obtained numerical results is made with previously published results in some special cases, and found to be in a good agreement.
\end{abstract}

Keywords: Laminar flow; Boundary layer; Stretching horizontal cylinder; Magnetic field; Heat source or sink; Suction or injection

\section{Introduction}

The boundary layer theory had been presented in 1904 by Prandtl [1]. The problem of boundary layer flow and heat transfer over a moving or stretching surface is of interest in numerous industrial applications such as polymer extrusion processes where the object enters the fluid for cooling below a certain temperature, hot rolling, paper production, wire drawing, aerodynamic extrusion of plastic sheets, the boundary layer along a liquid film and condensation process of metallic plate in a cooling bath and glass.

The boundary layer behaviour on moving surfaces in a viscous fluid at rest is considered by Sakiadis [2,3] whose work was subsequently extended by [4-14]. Lin and Shih [15,16] considered the laminar boundary layer and heat transfer along horizontally and vertically moving cylinders with constant velocity and found that the similarity solutions could not be obtained due to the curvature effect of the cylinder.

The steady flow of viscous and incompressible fluid outside of a stretching hollow cylinder in an ambient fluid at rest is studied by Wang [17]. General boundary-layer equations governing steady, laminar, hydromagnetic flow and heat and mass transfer over a permeable cylinder moving with a linear velocity in the presence of heat generation/absorption, chemical reaction, suction/injection effects and uniform transverse magnetic field are developed by Chamkha [18].

In the present work, the effect of magnetic field on flow and heat transfer of an incompressible viscous fluid over a stretching horizontal cylinder in the presence of heat source or sink with suction/injection is discussed numerically. The similarity solutions may be obtained by assuming that the cylinder is stretched with linear velocity in the axial direction. The present study may be regarded as an extension of Ishak and Nazar [19].

\section{Mathematical Formulation}

Consider a steady, axisymmetric boundary layer flow of an incompressible viscous fluid along a continuously stretching horizontal cylinder of radius $R$ subjected to a uniform magnetic field of intensity $B_{0}$ in the radial direction as shown in Figure 1. The cylinder is being stretched and the fluid is being moved along the axial direction $x$ and the radial coordinate $r$ is perpendicular to the cylinder axis. The stretched surface has the velocity $U_{w}(x)=U_{0}(x / \ell)$ and the temperature distribution $T_{w}(x)=T_{\infty}+T_{0}(x / \ell)^{n}$. If a heat source (sink) is existed and the effect of the induced magnetic field is neglected, the continuity, momentum and energy equations governing such type of flow will be written as

$$
\begin{aligned}
& \frac{\partial}{\partial x}(r u)+\frac{\partial}{\partial r}(r v)=0, \\
& u \frac{\partial u}{\partial x}+v \frac{\partial u}{\partial r}=\frac{v}{r} \frac{\partial}{\partial r}\left(r \frac{\partial u}{\partial r}\right)-\frac{\sigma B_{0}^{2}}{\rho} u, \\
& u \frac{\partial T}{\partial x}+v \frac{\partial T}{\partial r}=\frac{\alpha}{r} \frac{\partial}{\partial r}\left(r \frac{\partial T}{\partial r}\right)+\frac{\alpha Q_{0}}{\kappa}\left(T-T_{\infty}\right),
\end{aligned}
$$

subject to the boundary conditions

$$
\begin{aligned}
& u=U_{w}(x), v=V, T=T_{w}(x) \text { at } r=R, \\
& u \rightarrow 0, T \rightarrow T_{\infty} \text { as } r \rightarrow \infty,
\end{aligned}
$$

where $V$ is the uniform velocity of suction $(V<0)$ or injection $(V>0)$.

The equation of continuity is satisfied if we choose a stream function $\psi(x, r)$ such that $u=r^{-1} \partial \psi / \partial r$ and $v=-r^{-1} \partial \psi / \partial x$. The similarity transformations

$$
\begin{aligned}
& \eta=\frac{r^{2}-R^{2}}{2 R}\left(U_{w} / \nu x\right)^{1 / 2}, \psi(x, r)=R\left(U_{w} v x\right)^{1 / 2} f(\eta), \\
& \theta(\eta)=\frac{T-T_{\infty}}{T_{w}-T_{\infty}},
\end{aligned}
$$

will be substituted into equation (2) and equation (3) to obtain the

*Corresponding author: Elsayed MA Elbashbeshy, Department of Mathematics, Faculty of Science, Ain Shams University, Cairo, Egypt, Email: Elbashbeshy100@hotmail.com

Received March 26, 2012; Accepted April 21, 2012; Published April 23, 2012

Citation: Elbashbeshy EMA, Emam TG, El-Azab MS, Abdelgaber KM (2012) Effect of Magnetic Field on Flow and Heat Transfer over a Stretching Horizontal Cylinder in the Presence of a Heat Source/Sink with Suction/Injection. J Appl Mech Eng 1:106. doi:10.4172/2168-9873.1000106

Copyright: @ 2012 Elbashbeshy EMA, et al. This is an open-access article distributed under the terms of the Creative Commons Attribution License, which permits unrestricted use, distribution, and reproduction in any medium, provided the original author and source are credited. 


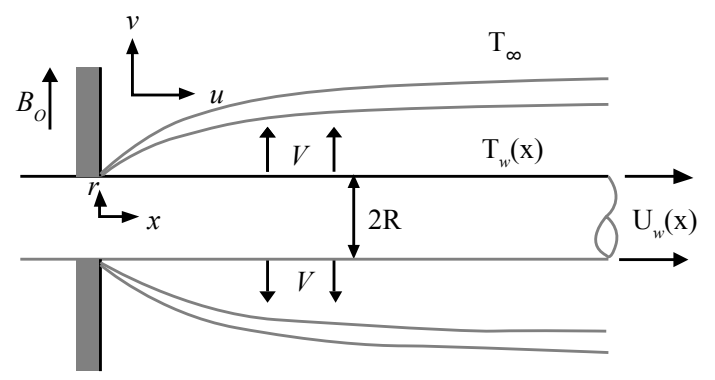

Figure 1: Physical model and coordinate system.

following system of ordinary differential equations

$$
\begin{aligned}
& (1+2 \gamma \eta) f^{\prime \prime \prime}+2 \gamma f^{\prime \prime}+f f^{\prime \prime}-f^{\prime 2}-M f^{\prime}=0, \\
& (1+2 \gamma \eta) \theta^{\prime \prime}+2 \gamma \theta^{\prime}+\operatorname{Pr}\left(f \theta^{\prime}-n f^{\prime} \theta\right)+\delta \theta=0,
\end{aligned}
$$

subject to the boundary conditions

$$
\begin{aligned}
& f(0)=-f_{0}, f^{\prime}(0)=1, \theta(0)=1, \\
& f^{\prime}(\infty) \rightarrow 0, \theta(\infty) \rightarrow 0,
\end{aligned}
$$

where the primes denote the differentiation with respect to $\eta$, $\gamma=R^{-1}\left(v \ell / U_{0}\right)^{1 / 2}$ is the curvature parameter, $M=\left(\sigma B_{0}^{2} \ell\right) /\left(\rho U_{0}\right)$ is the magnetic parameter, $\operatorname{Pr}=v / \alpha$ is the Prandtl number, $\delta=\left(v Q_{0} \ell\right) /\left(\kappa U_{0}\right)$ is the heat generation $(\delta>0)$ and absorption $(\delta<0)$ parameter and $f_{0}=\left(\ell / v U_{0}\right)^{1 / 2} V$ is the suction $\left(f_{0}<0\right)$ or injection $\left(f_{0}>0\right)$ parameter.

The physical quantities of interest here are the skin friction coefficient $C_{f}$ and the local Nusselt number $N u_{x}$ which are defined as

$$
C_{f}=\frac{2 \tau_{w}}{\rho U_{w}^{2}}, N_{u x}=\frac{x q_{w}}{\kappa\left(T_{w}-T_{\infty}\right)},
$$

where $\tau_{w}=-\mu(\partial u / \partial r)_{r=R}$ the surface is shear stress and $q_{w}=-\kappa(\partial T / \partial r)_{r=R}$ is the surface heat flux. Substituting the similarity transformations equation (5) into equation (9) yields

$$
\frac{1}{2} C_{f} \sqrt{\operatorname{Re}} \bar{x}=-f^{\prime \prime}(0), N_{u x} / \sqrt{\operatorname{Re}} \bar{x}=-\theta^{\prime}(0)
$$

where $\bar{x}=x / \ell$ and $\operatorname{Re}=\ell U_{w} / v$.

\section{Numerical Solution}

Equations (6) and (7) subject to the boundary condition (8) are converted into the following simultaneous system of first order differential equations as follows:

$$
\begin{aligned}
& y_{1}^{\prime}=y_{2}, \\
& y_{2}^{\prime}=y_{3}, \\
& y_{3}^{\prime}=\frac{1}{1+2 \gamma \eta}\left[-2 \gamma y_{3}-y_{1} y_{3}+y_{2}^{2}+M y_{2}\right], \\
& y_{4}^{\prime}=y_{5}, \\
& y_{5}^{\prime}=\frac{1}{1+2 \gamma \eta}\left[-2 \gamma y_{5}-\operatorname{Pr} y_{1} y_{5}+n \operatorname{Pr} y_{2} y_{4}-\delta y_{4}\right],
\end{aligned}
$$

where $y_{1}=f$ and $y_{4}=\theta$.

The initial conditions are

$$
y_{1}(0)=-f_{0}, y_{2}(0)=1, y_{3}(0)=s_{1}, y_{4}(0)=1, y_{5}(0)=s_{2},
$$

where $s_{1}$ and $s_{2}$ are priori unknowns to be determined as a part of the solution.

By using Mathematics, a function $F\left(s_{1}, s_{2}\right)$ is defined such that $F\left[s_{1}, s_{2}\right]=N D S o l v e[\operatorname{system}(11-12)]$. The values of $s_{1}$ and $s_{2}$ are determined upon solving the equations, $y_{2}\left(\eta_{\max }\right)=0$ and $y_{4}\left(\eta_{\max }\right)=0$. A suitable value of $\eta$ is taken and then increased to reach $\eta_{\max }$ such that the difference between two successive values of $s_{1}$ and those of $s_{2}$ is less than $10^{-7}$. Once $s_{1}$ and $s_{2}$ are determined, the system will be closed and can be solved numerically again using NDSolve to get the final results.

\section{Result and Discussion}

The computations have been carried out for various values of the previously defined parameters $\gamma, M, \operatorname{Pr}, n, \delta$ and $f_{0}$. The accuracy of the numerical scheme is checked out by performing various comparisons at different conditions with previously published papers. The results for the local Nusselt number, $-\theta^{\prime}(0)$, are compared with those reported in the references [8] for $\gamma=0$ (flat plate), $M=0$ (no magnetic field), $\delta=0$ (no heat source or sink) and $f_{0}=0$ (no suction/ injection) with different values of $\operatorname{Pr}$ and $n$ and they are found to be in a good agreement as shown in Table 1.

It is obvious that the value of skin friction coefficient, $-f^{\prime \prime}(0)$, is positive for all values of the different parameters as shown in Table 2 and Table 3. Physically, the positive value of $-f^{\prime \prime}(0)$ means the surface exerts a drag force on the fluid which is suitable for our present problem because the stretching cylinder will induce the flow. The value of $-f^{\prime \prime}(0)$ is neither influenced by the variance of the Prandtl number $\operatorname{Pr}$, the variance of the heat generation/absorption parameter $\delta$ nor the variance of the surface temperature exponent $n$ while the value of $-f^{\prime \prime}(0)$ is increased by increasing the curvature parameter $\gamma$ or the magnetic parameter $M$ as shown in table 2 and table 3 . On the other hand, value of $-f^{\prime \prime}(0)$ is decreased by increasing the suction/ injection parameter $f_{0}$. Hence, in order to minimize the skin friction value which we usually look for in an industrial application, one needs to decrease the magnetic field intensity and increase the radius of the stretching cylinder and the suction/injection velocity.

The value of local Nusselt number, $-\theta^{\prime}(0)$, is increased by increasing the curvature parameter $\gamma$ which means that the skin friction as well as the heat transfer rate at the surface are larger for a cylinder compared to the flat plate. Also, the value of $-\theta^{\prime}(0)$ is increased by increasing the surface temperature exponent $n$ and increasing the Prandtl number Pr which explained by the fact that the higher Prandtl number fluid

\begin{tabular}{|c|c|c|c|c|}
\hline $\operatorname{Pr}$ & $n$ & Grubka and Bobba [8] & Ishak and Nazar [24] & Present results \\
\hline 1 & -2 & -1.0000 & -1.0000 & -1.0000 \\
& -1 & 0.0 & 0.0 & 0.0 \\
& 0 & 0.5820 & 0.5820 & 0.5820 \\
& 1 & 1.0000 & 1.0000 & 1.0000 \\
& 2 & 1.3333 & 1.3333 & 1.3333 \\
\hline 10 & -2 & -10.0000 & -10.0000 & -10.0000 \\
& -1 & 0.0 & 0.0 & 0.0 \\
& 0 & 2.3080 & 2.3080 & 2.3080 \\
& 1 & 3.7207 & 3.7207 & 3.7207 \\
& 2 & 4.7969 & 4.7969 & 4.7969 \\
\hline
\end{tabular}

Table 1: Comparison of $-\theta^{\prime}(0)$ for various values of $\operatorname{Pr}$ and $n$ when $\gamma=M=\delta=f_{0}=0$ 


\begin{tabular}{|c|c|c|c|c|}
\hline Parameters (fixed values) & \multicolumn{2}{|c|}{$\begin{array}{l}\text { Parameter (dif- } \\
\text { ferent values) }\end{array}$} & \multirow{2}{*}{$\begin{array}{l}-f^{\prime \prime}(0) \\
0.7449 \\
0.9291 \\
1.1004\end{array}$} & \multirow{2}{*}{$\begin{array}{c}-\theta^{\prime}(0) \\
0.8071 \\
1.0063 \\
1.1881\end{array}$} \\
\hline $\operatorname{Pr}=0.7, M=0.3, n=1, \delta=-0.5, f_{0}=1$ & $\gamma$ & $\begin{array}{c}0 \\
0.5 \\
1\end{array}$ & & \\
\hline$\gamma=1, \operatorname{Pr}=0.7, n=1, \delta=-0.5, f_{0}=1$ & $M$ & $\begin{array}{l}0 \\
1 \\
2\end{array}$ & $\begin{array}{l}0.9497 \\
1.3880 \\
1.7139\end{array}$ & $\begin{array}{l}1.2084 \\
1.1541 \\
1.1215\end{array}$ \\
\hline$\gamma=1, M=0.3, n=1, \delta=-0.5, f_{0}=1$ & $\operatorname{Pr}$ & $\begin{array}{c}0.7 \\
3 \\
10\end{array}$ & $\begin{array}{l}1.1004 \\
1.1004 \\
1.1004\end{array}$ & $\begin{array}{l}1.1881 \\
1.2266 \\
1.3152\end{array}$ \\
\hline$\gamma=1, M=1, \operatorname{Pr}=0.7, \delta=-0.5, f_{0}=1$ & $n$ & $\begin{array}{c}-2 \\
-1 \\
0 \\
1 \\
2\end{array}$ & $\begin{array}{l}1.3880 \\
1.3880 \\
1.3880 \\
1.3880 \\
1.3880\end{array}$ & $\begin{array}{l}0.3567 \\
0.6593 \\
0.9216 \\
1.1541 \\
1.3636\end{array}$ \\
\hline$\gamma=1, M=1, \operatorname{Pr}=1, n=1, f_{0}=1$ & $\delta$ & $\begin{array}{c}-1 \\
-0.5 \\
-0.2\end{array}$ & $\begin{array}{l}1.3880 \\
1.3880 \\
1.3880\end{array}$ & $\begin{array}{l}1.3880 \\
1.1616 \\
0.9855\end{array}$ \\
\hline$\gamma=1, M=0.3, \operatorname{Pr}=0.7, n=1, \delta=-0.5$ & $f_{0}$ & $\begin{array}{c}-1 \\
0 \\
1\end{array}$ & $\begin{array}{l}2.0656 \\
1.5160 \\
1.1004\end{array}$ & $\begin{array}{l}1.8482 \\
1.4858 \\
1.1881\end{array}$ \\
\hline
\end{tabular}

Table 2: The values of $-f^{\prime \prime}(0)$ and $-\theta^{\prime}(0)$ for various values of $\gamma, M, \operatorname{Pr}, n, \delta$ and $f_{0}$.

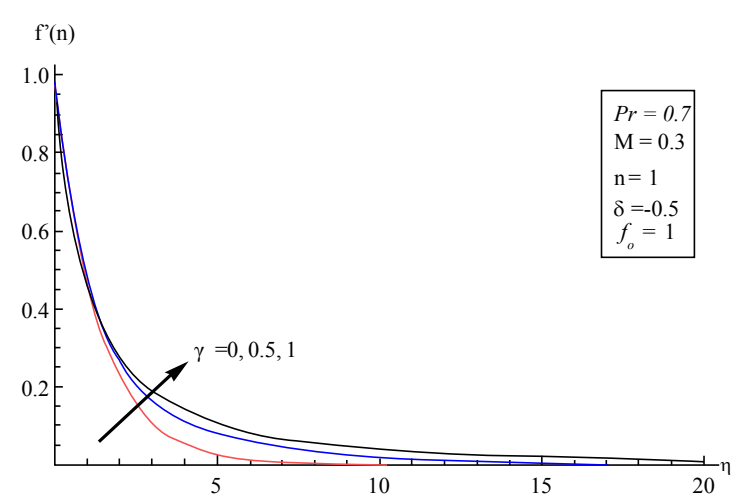

Figure 2: The velocity profiles $f^{\prime}(\eta)$ for various values of $\gamma$ at $\operatorname{Pr}=0.7, M=0.3, n=1, \delta=-0.5, f_{0}=1$.

has a lower thermal conductivity (or a higher viscosity) hence its thermal boundary layer will be the thinner and its heat transfer will be the higher. On the other hand, the value of $-\theta^{\prime}(0)$ is decreased slightly by increasing the magnetic parameter $M$ due to the increase of resistance, produced by the transverse magnetic field Lorentz force, to the fluid transport phenomena hence the fluid thermal boundary layer will be thick and its heat transfer will decrease. Also, it is decreased by increasing the heat generation/absorption parameter $\delta$ which is expected since the heat generation mechanism creates a layer of hot fluid near the surface which in turn reduces the rate of heat transfer from the surface. Finally, it is decreased by increasing the suction/ injection parameter $f_{0}$ which is expected since the suction velocity will slow down the flow.

The velocity profiles for various values of $\gamma, M$ and $f_{0}$ are presented in the figures from Figure 2 to Figure 4, respectively. Also, the temperature profiles for various values of $\gamma, M, \operatorname{Pr}, n, \delta$ and $f_{0}$ are presented in the Figures from Figure 5 to Figure 10, respectively. From Figure 2 and Figure 5, a cross over is found for varying the curvature parameter. The velocity and the temperature near the

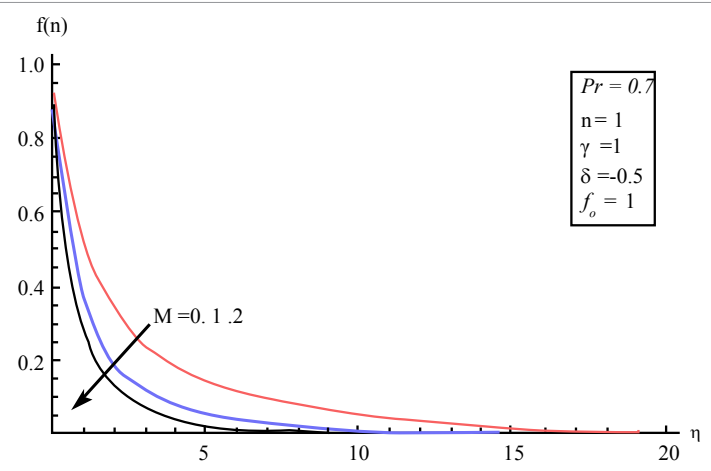

Figure 3: The velocity profiles $f^{\prime}(\eta)$ for various values of $M$ at $\operatorname{Pr}=0.7, \gamma=1, n=1, \delta=-0.5, f_{0}=1$

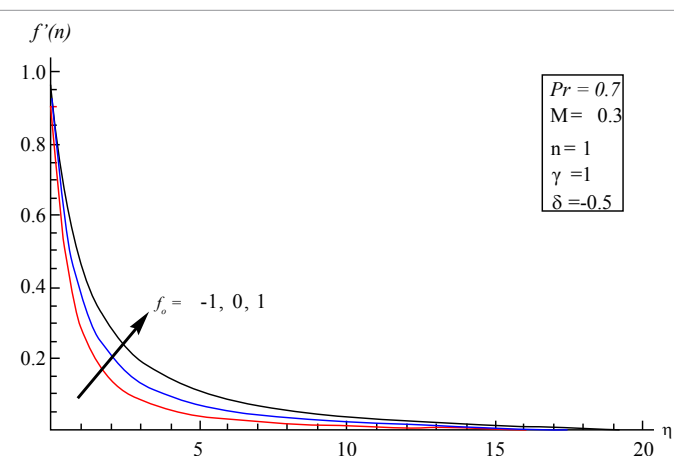

Figure 4: The velocity profiles $f^{\prime}(\eta)$ for various values of $f_{0}$ at $\operatorname{Pr}=0.7, M=0.3, \gamma=1, \quad n=1, \delta=-0.5$

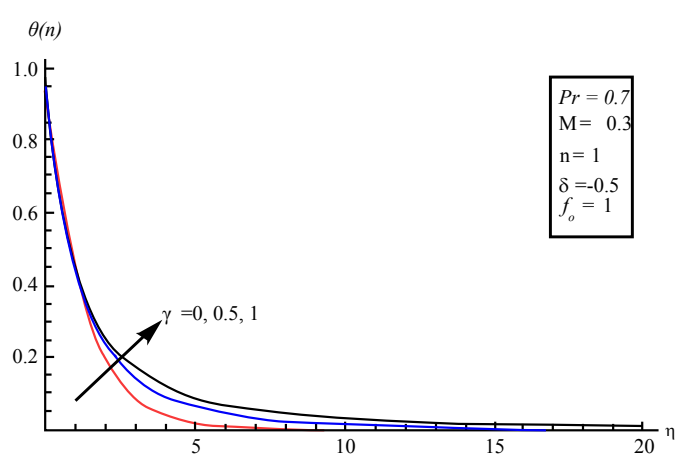

Figure 5: The temperature profiles $\theta(\eta)$ for various values of $\gamma$ at $\operatorname{Pr}=0.7, M=0.3, n=1, \delta=-0.5, f_{0}=1$

stretching surface decrease with raising the curvature parameter $\gamma$ while far from the stretching surface. If the magnetic parameter $M$ is increased, the velocity boundary layer is decreased while the temperature boundary layer is slightly increased as shown in Figure 3 and Figure 6. The influence of increasing the Prandtl number Pr or the surface temperature exponent $n$ is to decrease the temperature boundary layer as shown in Figure 7 and Figure 8, respectively. On the other hand, increasing the heat generation/absorption parameter $\delta$ leads to increase the temperature boundary layer as shown in Figure 9. The effect of suction/injection parameter $f_{0}$ is to increase the velocity and the temperature boundary layers as shown in Figure 4 and Figure 10 respectively. 


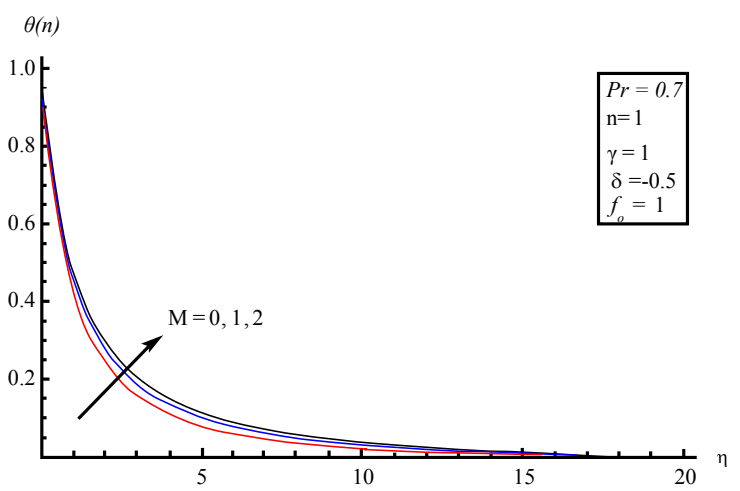

Figure 6: The temperature profiles $\theta(\eta)$ for various values of $M$ at $\operatorname{Pr}=0.7, \gamma=1, n=1, \delta=-0.5, f_{0}=1$.

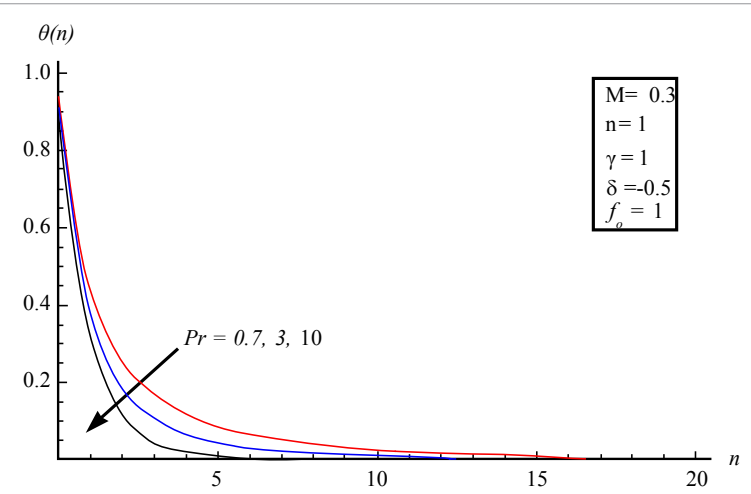

Figure 7: The temperature profiles $\theta(\eta)$ for various values of $\operatorname{Pr}$ at $M=0.3, \gamma=1, n=1, \delta=-0.5, f_{0}=1$

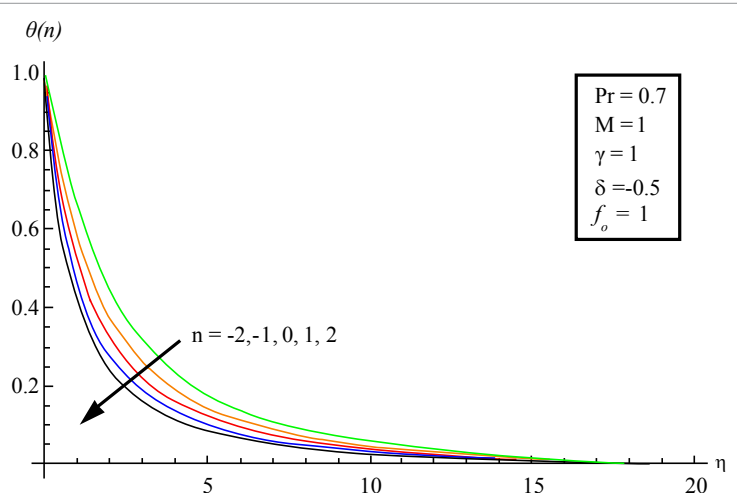

Figure 8: The temperature profiles $\theta(\eta)$ for various values of $n$ at $\operatorname{Pr}=0.7, M=1, \gamma=1, \delta=-0.5, f_{0}=1$

\section{Conclusion}

Numerical solutions have been obtained for the laminar boundary layer flow along a horizontal cylinder affected by a uniform magnetic field in the radial direction in the presence of heat source or sink with suction/injection. An appropriate similarity transforms were used to transform the momentum and the energy equations into a set of ordinary differential equations which are solved by using Mathematical. Numerical computations show that the present values of the rate of heat

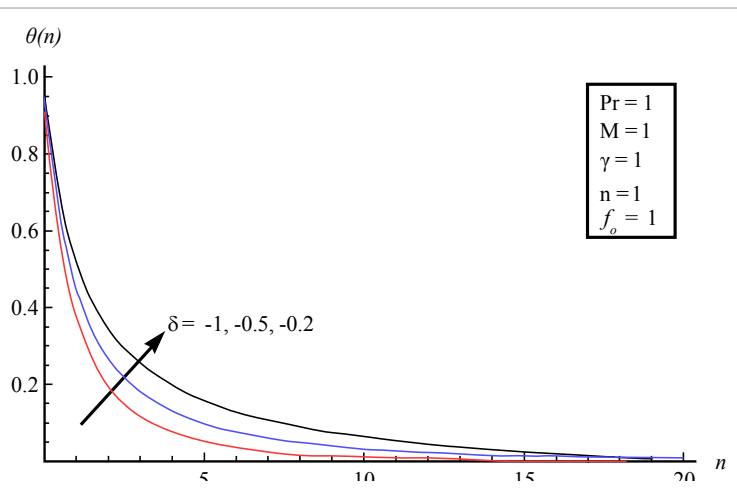

Figure 9: The temperature profiles $\theta(\eta)$ for various values of $\delta$ at $\operatorname{Pr}=1, M=1, \gamma=1, n=1, f_{0}=1$

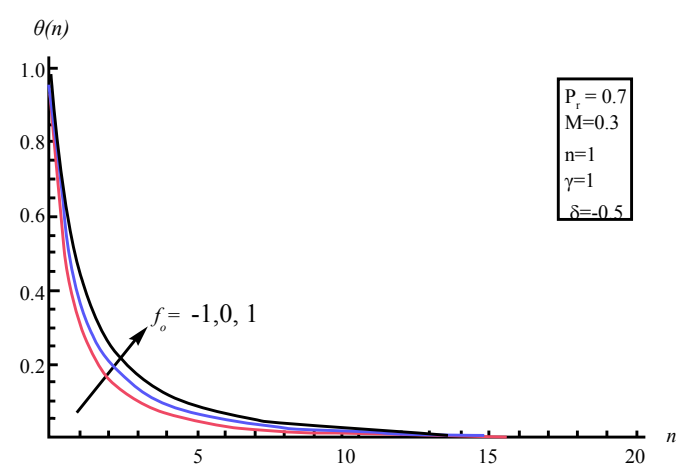

Figure 10: The temperature profiles $\theta(\eta)$ for various values of $f_{0}$ at $\operatorname{Pr}=0.7, M=0.3, \gamma=1, n=1, \delta=-0.5$

transfer are in a great agreement with those obtained by previous investigations. The following results are obtained:

1. The fluid velocity and temperature increase with the increase in the curvature parameter far from the stretching surface while they show the reverse near the stretching surface.

2. The fluid velocity increases with the increase in the suction/ injection parameter while it decreases with the increase in the magnetic parameter.

3. The fluid temperature increases with the increase in the magnetic, heat generation/absorption and the suction/injection parameters while it decreases with the increase in the Prandtl number and the surface temperature exponent.

4. The skin friction can be minimized by decreasing the magnetic field intensity and increasing the radius of the stretching cylinder and the suction/injection velocity.

\section{Nomenclature}

$B_{0}$ - Magnetic field intensity

$C_{f}$ - Local skin friction coefficient

$f$ - Dimensionless stress functions

$f_{0}$ - Suction/injection parameter

$M$ - Magnetic parameter 
Citation: Elbashbeshy EMA, Emam TG, El-Azab MS, Abdelgaber KM (2012) Effect of Magnetic Field on Flow and Heat Transfer over a Stretching Horizontal Cylinder in the Presence of a Heat Source/Sink with Suction/Injection. J Appl Mech Eng 1:106. doi:10.4172/2168-9873.1000106

Page 5 of 5

$N_{u x}$ - Nusselt number

$n$ - Surface temperature exponent

Pr - Prandtl number

$Q_{0}$ - Uniform volumetric heat generation or absorption constant

$q_{w}$ - Surface heat flux

Re - Reynolds number

$T$ - Fluid temperature

$T_{w}$ - Temperature distribution of the stretching surface

$T_{0}$ - Reference temperature of fluid

$T_{\infty}$ - Ambient temperature of fluid

$u$ - Fluid velocity along the -axis

$U_{w}$-Stretching surface velocity

$U_{0}$ - Reference velocity

$v$ - Fluid velocity along the -axis

$V$ - Suction/injection velocity

$\boldsymbol{r}$ - Radial coordinate perpendicular to the cylinder axis

$x$ - Axial coordinate of the cylinder

Greek letters

$\alpha$ - Thermal diffusivity

$\delta$ - Heat generation/absorption parameter

$\gamma$-Curvature parameter

$\eta$ - Dimensionless variable

$\theta$ - Dimensionless temperature function

$\kappa$ - Thermal conductivity

$\mu$ - Fluid dynamic viscosity

$\boldsymbol{V}$ - Fluid kinematic viscosity

$\rho$ - Fluid density

$\sigma$ - Electrical conductivity

$\tau_{w}$ - Surface shear stress

$\psi$ - Stream function

$\ell$ - Characteristic length

Superscript

1 - Differentiation with respect to $\eta$

Subscripts

$w$ - Stretching surface conditions

0 - Fluid reference conditions

$\infty$ - Fluid ambient conditions

\section{References}

1. Schlichting $H$ (1968) Boundary layer theory. (6thedn), McGraw-Hill, New York.

2. Sakiadis BC (1961) Boundary layer behavior on continuous solid surfaces: I. Boundary layer equations for two dimensional and axisymmetric flow. AIChE J 7: 26-28.

3. Sakiadis BC (1961) Boundary layer behaviour on continuous solid surfaces:II. The Boundary layer equations on a continuous flat surface. AIChE J 7: 221-225
4. Crane LJ (1970) Flow past a stretching plane. Z. Angew Math Phys 21: 645 647

5. Vleggaar J (1977) Laminar boundary layer behaviour on continuous, accelerating surfaces. Chem Eng Sci 32: 1517-1525.

6. Gupta PS, Gupta AS (1977) Heat and mass transfer on a stretching sheet with suction or blowing. Can J Chem Eng 55: 744-746.

7. Soundalgekar VM, Ramana Murthy TV (1980) Heat transfer in flow past a continuous moving plate with variable temperature. Heat Mass Transf 14: 91 93.

8. Grubka LJ, Bobba KM (1985) Heat transfer characteristics of a continuous stretching surface with variable temperature. J Heat Transfer 107: 248-250.

9. Ali ME (1994) Heat transfer characteristics of a continuous stretching surface. Heat Mass Transf 29: 227-234.

10. Banks WHH (1983) Similarity solutions of the boundary layer equations for a stretching wall. Journal de Mecanique Theorique et Appliquee 2: 375-392.

11. Ali ME (1995) On thermal boundary layer on a power-law stretched surface with suction or injection. International Journal of Heat and Fluid Flow 16: 280-290.

12. Elbashbeshy EMA (1998) Heat transfer over a stretching surface with variable surface heat flux. J Phys D Appl Phys 31: 1951.

13. Ishak A, Nazar R, Pop I (2006) Unsteady Mixed Convection Boundary Laye Flow Due to a Stretching Vertical Surface. The Arabian Journal For Science And Engineering 31: 165-182.

14. Elbashbeshy EMA, Bazid MAA (2000) Heat transfer over a continuously moving plate embedded in non-Darcian porous medium. Int $\mathrm{J}$ Heat Mass Transf 43 3087-3092.

15. Lin HT, Shih YP (1980) Laminar boundary layer heat transfer along static and moving cylinders. Journal of the Chinese Institute of Engineers 3: 73-79.

16. Lin HT, Shih YP (1981) Buoyancy effects on the laminar boundary layer heat transfer along vertically moving cylinders. Journal of the Chinese Institute of Engineers 4: 47-51.

17. Wang CY (1988) Fluid flow due to a stretching cylinder. Phys Fluids 31.

18. Chamkha AJ (2011) Heat and mass transfer from MHD flow over a moving permeable cylinder with heat generation or absorption and chemical reaction. Communications in Numerical Analysis.

19. Ishak A, Nazar R (2009) Laminar Boundary Layer Flow Along A Stretching Cylinder. European Journal of Scientific Research 36: 22-29. 